\title{
Reclaiming Conversation: The Power of Talk in a Digital Age
}

\author{
Author: Sherry Turkle
}

Published by: Penguin Press, 2015

Reviewed by: Tori Callais, Department of Higher Education, Loyola University Chicago

"The moment is right. We had a love affair with a technology that seemed magical. But like great magic, it worked by commanding our attention and not letting us see anything but what the magician wanted us to see. Now we are ready to reclaim our attention, for solitude, for friendship, for society" (Turkle, 2015, p. 377). In Sherry Turkle's Reclaiming Conversations: The Power of Talk in a Digital Age she critically analyzes how humans have turned away from conversation in favor of digital communication. As humans' desire for connection increases and their face-to-face conversations decrease, the consequences are troubling. The movement to "connect" via screen versus in person has created an environment in which children are struggling to learn empathy and build relationships. The ability to be in solitude and self-reflect has become more difficult and people are relying on others for their own sense of self. Although these consequences of digital communication are disconcerting, Turkle does not suggest that we abandon digital communication entirely. Instead she speaks to the curing ability of face-to-face conversations and reclaiming the space to normalize this. Although technology is useful and has a purpose, she argues that it should not be used to replace face-to-face communication. Machines, like Apple's Siri assistant, can assist us with 
getting quick information, but they cannot replace human interactions. Machines are not made to embody the complexity needed to be a human.

According to her bio, Sherry Turkle is not only a clinical psychologist and sociologist at Massachusetts Institute of Technology (MIT), but has also spent 30 years studying the human relationship with technology and is the founder of the MIT Initiative of Technology and Self. She has authored five books and three edited collections. One of her more wellknown works is Alone Together: Why We Expect More from Technology and Less from Each Other, which documents the embracement of smartphones and new technology.

After reading Reclaiming Conversation, I found strengths of this book included the book structure and layout, Turkle's ability to summarize her findings in a simple way, and her non-dismissal of using technology. Reclaiming Conversation takes a unique approach in terms of structure. Turkle uses Henry David Thoreau's Walden concept and quote, "I had three chairs in my house; one for solitude, two for friendship and three for society" to section her arguments throughout the book. The first chair for solitude is used to describe how we use technology to avoid being alone. The second chair for friendship is used to describe how relationships can be damaged by the attention we give our smartphones and the inattention we give our friends and family in person. The third chair is used to describe how digital communication has changed our different environments from school, work, home, etc. Turkle even includes a fourth chair that raises the question, "Who do we become when we talk to machines" (p. 349). The fourth chair section, the shortest in the book, raises questions about replacing human interactions with machines (Apple's Siri assistant and emotive robots). This structure allows for the reader to consider the impact of constant digital communication from the micro to macro levels. The reader can first reflect on their relationship with digital communication and technology and then strategize on how technology influences our relationships and society as a whole. Throughout reading the book, I found myself reflecting on my own usage of digital communication and the amount of face-to-face interaction I have 
in different environments. The structure of this book allowed me to apply what I was reading to my own life; I found it to be engaging and a good opportunity for self-reflection.

I have often found that when people speak or write about the negative use of technology, they lack solutions or their solution is to abandon technology all together. As Turkle said, "We are being silenced by our technologies - in a way, cured of talking. These silences - often in the presence of our children - have led to a crisis of empathy that has diminished us at home, at work, and in public life. I've said that the remedy, most simply, is a talking cure" (p. 9). Turkle does not advocate for the elimination of technology, instead she argues that technology has value but that it cannot achieve what face-to-face conversation does. Technology is present in almost every aspect of everyday life and to completely eliminate it would not be practical, efficient, or reasonable. She presents research that supports talking and in-person conversation to remedy the consequences caused by digital communication. In creating spaces to re-introduce these remedy conversations, she suggests having no phone dinners and uni-tasking instead of multitasking, as stepping stones. There may not be a one-size-fits-all approach, but people can take efforts at home, at their places of work, and with friends and family to regain the ability to connect with others in a more meaningful way.

Turkle can be considered an outsider to the Millennial and Generation Z groups. Without her intentional decision to include these generations' specific stories in combination with her research, I do not believe this book would resonate well with larger audiences. Her decision to tell stories, while also presenting data from research studies, helps to create a more holistic picture of what people, from older to younger, are currently experiencing when it comes to digital and in-person communication. Turkle mentions how younger people are beginning to express their frustration with the continuous distribution of digital communication when they are in person with their friends and family members. Younger generations are expressing their own need for changing their digital communication habits, which gives hope that a change can occur with their buy in. 
I believe Reclaiming Conversation would make a great addition for a common reader for students. Digital communication has become a normalized part of life, especially with Millennials and Generation Z students. This book can help students, who do not know a time without smartphones, create a space to critically engage the pros and cons of this type of communication. "Without conversation, studies show that we are less empathetic, less connected, less creative and fulfilled. We are diminished, in retreat. But to generations that grew up using their phones to text and message, these studies may be describing losses they don't feel. They didn't grow up with a lot of face-to-face talk" (p. 13). Her findings may resonate with some, but also may alienate members from younger generations. Utilizing this book for students as a tool to self-reflect and then analyze at more macro levels can inform communication styles, self-image, student development, and even orientation, transition, and retention programming.

In terms of orientation, transition, and retention programming, this book emphasizes face-to-face conversations and the positive outcomes of having those. Turkle's research highlighted in this book can be beneficial in examining the importance of activities that involve oneon-one communication and group communication, such as small group meetings, icebreakers, requesting no phones policies, etc. It also can be used as a resource for conversations around vulnerability and empathy in leadership development.

Overall, Turkle does an excellent job of showing how face-toface conversation can "cure" the consequences of constant digital communication. We are craving connection more than ever as a society, but isolating ourselves with our smartphones is not the answer and neither is discarding them. Conversation, in person and frequent, is our opportunity to reclaim this connection we desire. 